\title{
A diagnosis of rainfall over South America during 1997/98 El Niño and 1998/99 La Niña events: Comparison between TRMM PR and GPCP rainfall estimates
}

\author{
Sergio H Franchito*, V Brahmananda Rao, Ana C Vasques, \\ Clovis M E Santo and Jorge C Conforte \\ Centro de Previsão de Tempo e Estudos Climáticos, CPTEC Instituto Nacional de Pesquisas Espaciais, \\ INPE CP 515, 12245-970, São José dos Campos, SP, Brazil. \\ *e-mail: sergio.franchito@cptec.inpe.br
}

A comparison between TRMM PR rainfall estimates and rain gauge data from ANEEL and combined gauge/satellite data from GPCP over South America (SA) is made. In general, the annual and seasonal regional characteristics of rainfall over SA are qualitatively well reproduced by TRMM PR and GPCP. It is found that over most of SA GPCP exceeds TRMM PR rainfall. The largest positive differences between GPCP and TRMM PR data occur in the north SA, northwestern and central Amazonia. However, there are regions where GPCP rainfall is lower than TRMM PR, particularly in the Pacific coastal regions and in southern Brazil. We suggest that the cause for the positive differences GPCP minus TRMM PR rainfall are related to the fact that satellite observations based on infrared radiation and outgoing longwave radiance sensors overestimate convective rainfall in GPCP and the cause for the negative differences are due to the random errors in TRMM PR. Rainfall differences in the latter phases of the 1997/98 El Niño and 1998/99 La Niña are analyzed. The results showed that the rainfall anomalies are generally higher in GPCP than in TRMM $\mathrm{PR}$, however, as in the mean annual case, there are regions where the rainfall in GPCP is lower than in TRMM PR. The higher positive (negative) differences between the rainfall anomalies in GPCP and TRMM PR, which occur in the central Amazonia (southern Brazil), are reduced (increased) in the El Niño event. This is due to the fact that during the El Niño episode the rainfall decreases in the central Amazonia and increases in the southern Brazil. Consequently, the overestimation of the convective rainfall by GPCP is reduced and the overestimation of the rainfall by TRMM PR is increased in these two regions, respectively.

\section{Introduction}

Due to their influence on global climate, El NiñoLa Niña events have received much attention in recent years. The strongest Pacific warm episode (El Niño) in the historical record occurred from the end of 1997 up to May 1998 (Coughlan 1999; Neelin et al 2000). The development of this episode relative to the previous events was discussed by Wang and Weisberg (2000). During the later part of 1998 up to the beginning of 1999 Pacific cold episode (La Niña) conditions prevailed.
The impact of El Niño-Southern Oscillation (ENSO) on rainfall over South America (SA) has been studied extensively (Ropelewski and Halpert 1987, 1989; Aceituno 1988; Rao and Hada 1990; Grimm et al 1998; and others). To investigate the climate effects of ENSO over SA several precipitation data sources are available. The values of precipitation obtained from different data sources show differences in various regions of the continent. Thus, there is a need to know the potentialities and limitations of the available data sources of precipitation. In an earlier study, Rao et al (2002)

Keywords. TRMM PR data; GPCP data; rainfall estimates over South America. 
made a detailed diagnosis of rainfall over SA during the 1997/98 El Niño event comparing the National Centers for Environmental Predictions/National Center for Atmospheric Research (NCEP/NCAR) reanalysis rainfall data and the Agência Nacional de Energia Elétrica (ANEEL) rain gauge data over Brazil.

On 27 November 1997, the Tropical Rainfall Measuring Mission (TRMM) satellite was launched. TRMM Precipitation Radar (PR) is the first active satellite microwave instrument for measuring three-dimensional structures of rainfall over the tropics and subtropics (Simpson et al 1998; Kummerow et al 2000). In a recent paper, Franchito et al (2009) validated TRMM PRLevel 3 (version 5) over Brazil comparing with rain gauge station data from ANEEL. This study considered Brazilian regions where there was a dense ANEEL rain gauge concentration. However, it is instructive to investigate the potentialities and limitations of TRMM PR rainfall estimates not only over regions where there is a dense concentration of rain gauge stations, but also over regions where they are sparse. This is highly relevant because in regions without dense rain gauge stations, the information about precipitation must be obtained from another available data source, such as satellite-based sensors and radar information. $\mathrm{Li}$ and $\mathrm{Fu}$ (2005) compared TRMM PR data with the Global Precipitation Climatology Project (GPCP) version 2 for the period 1998-2000. They noted that although the pattern distribution of rainfall is in agreement in the two data sources, there are significant quantitative differences in the regions of intense rainfall over the tropical oceans and their vicinity. The most significant absolute difference of greater than $2 \mathrm{~mm}$ day $^{-1}$ is found in the Pacific ITCZ and its northern brim. In general, the mean rainfall over the tropical oceans are lower (around $0.45 \mathrm{~mm}$ day $^{-1}$ on average) in the TRMM data than in GPCP data. They also compared the rainfall distribution in TRMM PR and GPCP over the tropical Pacific Ocean during the latter phases of the 1997/98 El Niño and 1998/99 La Niña. They noted that rainfall over the entire tropical Pacific Ocean is greatly overestimated by GPCP compared to TRMM PR during the latter phase of this El Niño while in the same period of La Niña, the amplitude and area of the rainfall difference between both datasets are small. $\mathrm{Li}$ and $\mathrm{Fu}$ (2005) made an attempt to compare TRMM PR with GPCP mainly in the tropical ocean regions, where the differences between the rainfall estimates from the two sources are larger. The differences in the land regions were analyzed considering different latitude belts. Since rainfall in the tropics is caused by different small-scale mechanisms in the different regions in a latitude belt, studies aimed to validate TRMM PR rainfall estimates over specific continental regions are needed.

The purpose of the present study is to make a detailed diagnosis of rainfall over SA during the 1997/98 El Niño and 1998/99 La Niña events using rainfall obtained from TRMM PR. In particular, we attempt to investigate the potentialities and limitations of TRMM PR data to reproduce the rainfall distribution over this region compared with rain gauge station data from ANEEL and combined satellite/station data from GPCP.

\section{Data sources}

In the present study we use the accumulated monthly rainfall time series from the TRMM PRLevel 3 (version 5), which is designed as 3A25G2 (http://helios.eorc.jaxa.jp/pub/TRMM/L3_data/ Ver/). These data are available at a high resolution grid $\left(0.5^{\circ} \times 0.5^{\circ}\right.$, latitude $\times$ longitude $)$. TRMM PR scanning width of about $220 \mathrm{~km}$ measures the rainfall rate from the earth surface to $20 \mathrm{~km}$ altitude with a horizontal resolution of $4.3 \mathrm{~km}$ at nadir and a vertical resolution of $0.25 \mathrm{~km}$ (Kummerow et al 1998). The rainfall rates are calculated from radar reflectivity with corrections for attenuation based on Iguchi and Meneghini (1994), Iguchi et al (2000) and Meneghini et al (2000). TRMM $\mathrm{PR}$ provides information on the three-dimensional structure of rainfall. Besides the rainfall intensity, TRMM PR also contains information on rain types including stratiform, convective and others. Several papers give a detailed description of TRMM PR products and applications (Adler et al 2000; $\mathrm{Fu}$ and Liu 2001, 2003; Kummerow et al 2004; Fu et al 2003; Zheng et al 2004).

GPCP data merges precipitation datasets involving measurements of rain gauge from the Global Precipitation Climatology Center (GPCC) (Rudolf 1993; Rudolf et al 1994) with various satellite-based observations, such as GPI (Arkin and Meisner 1987), OPI (Xie and Arkin 1998), SSM/I emission (Wilheit et al 1991), SSM/I scattering (Ferraro and Marks 1995; Ferraro et al 1996) and TOVS (Susskind et al 1997). GPCP data are available since 1979. We use the rainfall data obtained from GPCP version 2 (Huffman et al 1997; Adler et al 2003) (http:// lwf.ncdc.noaa.gov/oa/wmo/wdcamet-ncdc.html). These data are in a $2.5^{\circ} \times 2.5^{\circ}$, latitude $\times$ longitude grid.

Rain gauge station data for Brazil from ANEEL are available for the period 1979-2000 for a large number of stations (figure 1). The data were checked for consistency (deleting unreasonable values from a climatological viewpoint) and are available at http://hidroweb.aneel.gov.br. As can be 


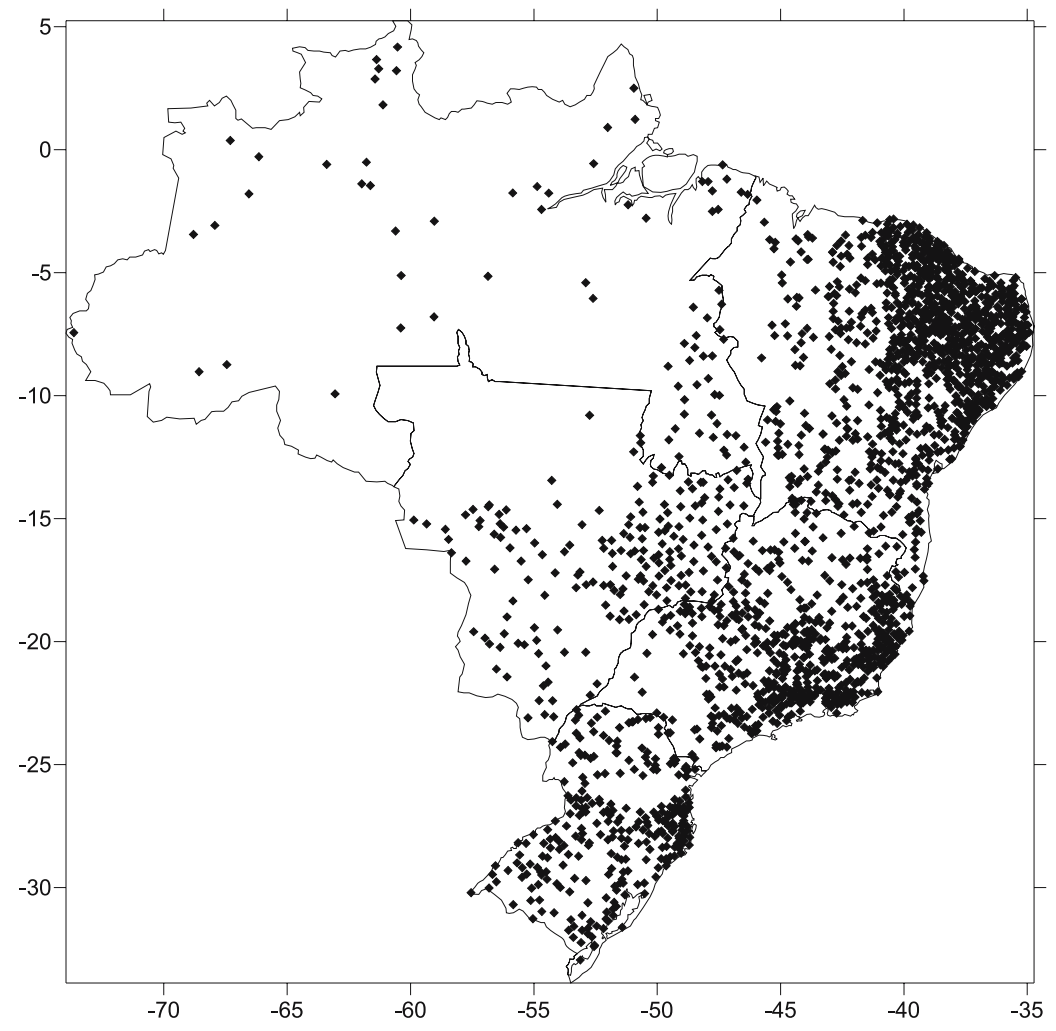

Figure 1. Distribution of the ANEEL stations.

seen in figure 1 , there is a dense network of rain gauge stations in the northeast, while the rain gauges are barely available in some regions, such as Amazonia and central Brazil.

In order to obtain spatial homogeneity, in the present study the values of rainfall obtained from TRMM are extrapolated to $2.5^{\circ} \times 2.5^{\circ}$, latitude $\times$ longitude intervals and the rainfall data from ANEEL are averaged at each $2.5^{\circ} \times 2.5^{\circ}$ grid.

Since TRMM PR data are available only from 1998, we concentrate our analysis for the periods JFMA 1998 and JFMA 1999, which correspond to the latter phases of the El Niño and La Niña, respectively. Although the main objective of the paper is to study the rainfall anomalies for these El Niño and La Niña events, we also attempt to analyze the characteristics of mean rainfall over SA for the period 1998-2005. Comparisons of the rainfall averaged over this period are made between TRMM PR and GPCP data since the ANEEL data are available only up to year 2000 .

\subsection{Data source errors}

TRMM monthly rainfall estimates contain errors due to discrete temporal sampling and remote spaceborne rain retrievals. Many studies have focused the problems of the sampling errors in TRMM (Shin and North 1988; North and
Nakamoto 1989; Bell et al 1990, 2001; Bell and Kundu 2000, among others). More recently, Franchito et al (2009) discussed the errors inherent to TRMM PR monthly rainfall estimates, particularly over Brazil. They noted that the random and systematic errors of TRMM PR are sensitive to seasonal and regional differences. During DJF and MAM TRMM PR rainfall is reliable over Brazil. In JJA (SON) TRMM PR estimates are only reliable in the Amazonian and southern (Amazonian and southeastern) regions. They commented that the standard deviation (SD) values are around 2-3 $\mathrm{mm} \mathrm{h}^{-1}$ in the central and southeast regions of Brazil, and $3-4 \mathrm{~mm} \mathrm{~h}^{-1}$ in Amazonia. The largest values occur in the southern region $\left(4-5 \mathrm{~mm} \mathrm{~h}^{-1}\right)$.

GPCP precipitation estimates over land are mainly generated by rain gauge. Gridded rain gauge precipitation is subject to systematic errors (losses due to aerodynamic effects), sampling error (due to poor station density) and a methodical error (due to the interpolation method). Intercomparison studies by GPCC revealed that the methodical error is much smaller than the sampling error. It has been found necessary to have at least five gauges in a $2.5^{\circ} \times 2.5^{\circ}$ grid box to reduce sampling errors to within $10 \%$ (Legates and Willmott 1990). Details of the sampling error and availability of data are discussed by Rudolf et al $(1994,1998)$. In addition to the errors related 
with rain gauge data there are errors inherent to the satellite-based observations. The geosynchronous infrared (IR) based estimates employ the Geostationary Operational Environmental Satellite (GOES) Precipitation Index (GPI; Arkin and Meisner 1987) technique, which relates cold cloud top area to rain rate. The OPI technique (Xie and Arkin 1998) is based on the use of low-Earthorbit satellite OLR (outgoing longwave radiation) observations. Lower OLR radiances are directly related to higher cloud tops, which are related to increased precipitation rates (Adler et al 2003). However, non-precipitating high clouds like cirrus also show low values of OLR so that an overestimation of precipitation is expected (Franchito et al 2008; Marengo et al 2001). Thus, OLR rainfall derived from precipitation datasets (Xie and Arkin 1998) includes several false returns from the overhanging cirrus (and related cloud tops) (Fu and Liu 2003). In the particular case of Brazil, the largest random errors (which include algorithm and sampling error) for the mean period 1998-2005 occur in the north region and Amazonia (higher than $8 \mathrm{~mm}$ day $^{-1}$ ), which are regions with sparse rain gauge distribution, while in the southern and northeast regions, where there is a dense concentration of rain gauge stations, the errors are lesser (4-6 mm day ${ }^{-1}$, and less than $2 \mathrm{~mm}$ day $^{-1}$, respectively) (Franchito et al 2009).

\section{Characteristics of rainfall over SA in TRMM and GPCP data}

Figure 2(a-c) shows the mean annual rainfall for the period 1998-2005 from TRMM PR and GPCP datasets, and the differences (GPCP minus TRMM PR), respectively. As can be seen in these figures, there are differences and similarities in the rainfall values between the two datasets. Both data sources show low rainfall (values less than $900 \mathrm{~mm}$ ) in the interior of the northeast Brazil.
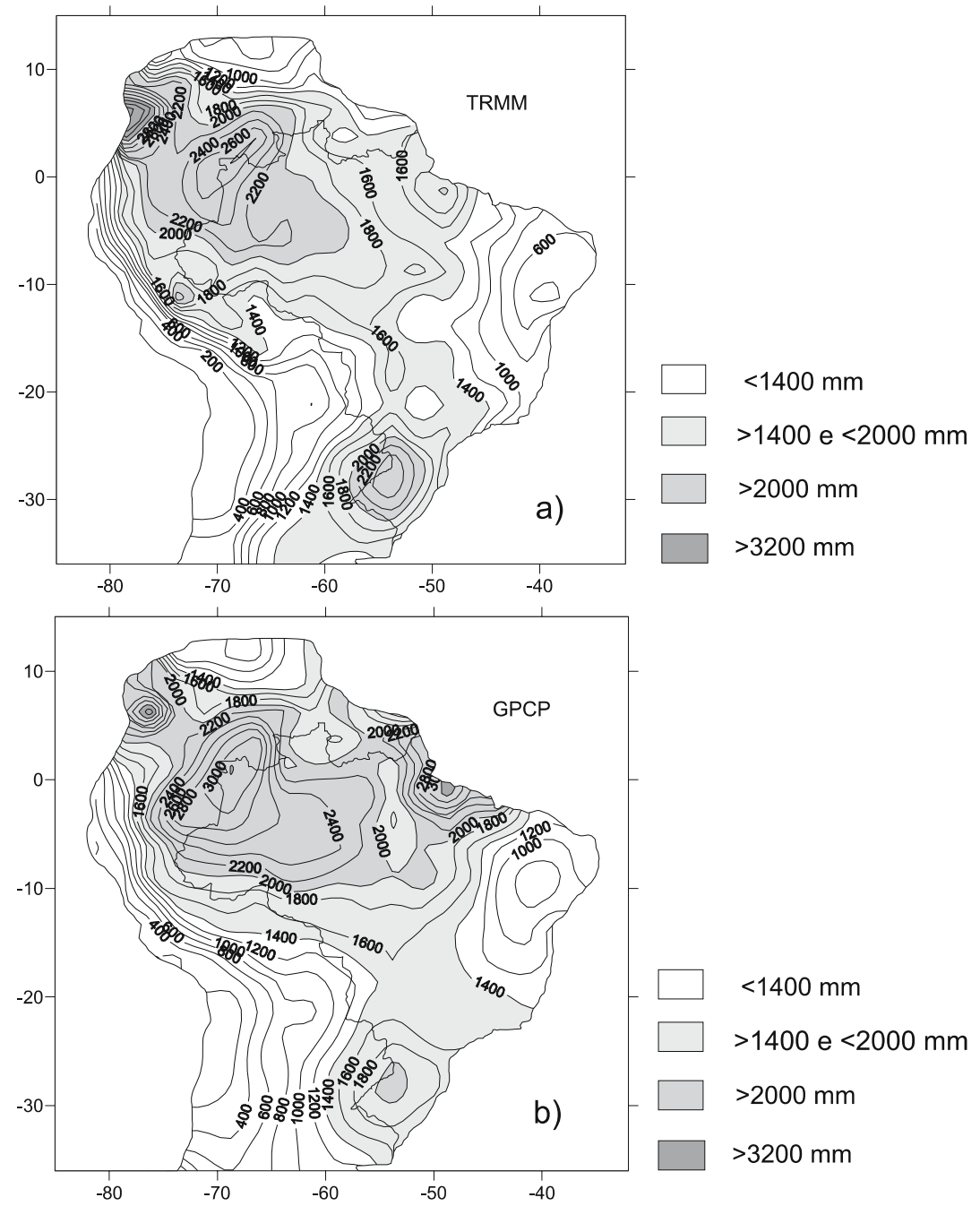

Figure 2. Mean annual precipitation (mm) (1998-2005): (a) TRMM, (b) GPCP, (c) GPCP minus TRMM precipitation, and (d) ANEEL data (1979-2000). 

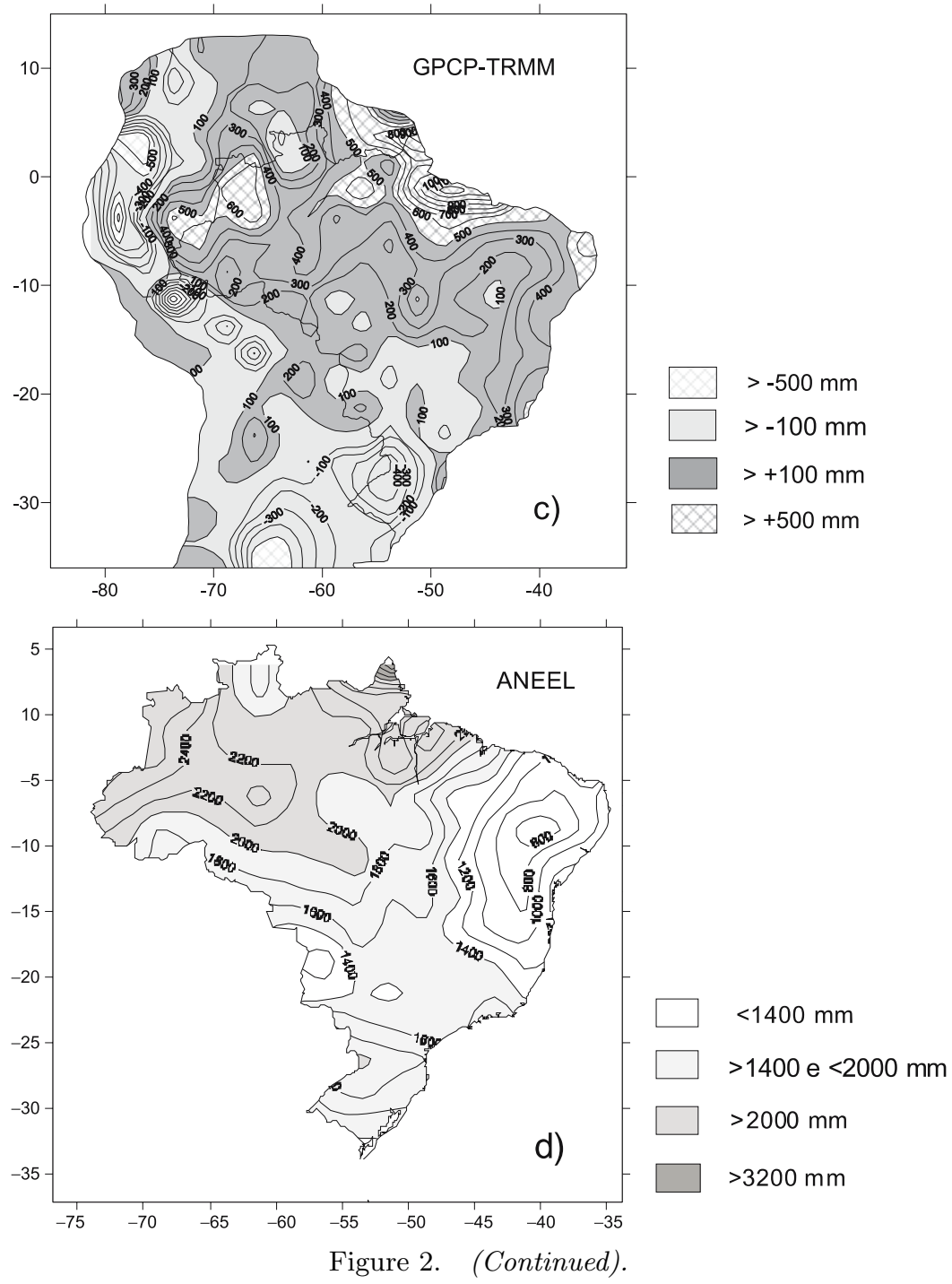

This is in agreement with the rainfall amounts in this region for the period 1979-2000 using ANEEL data (figure 2d). High rainfall in the northwestern Amazonia and southern Brazil is seen in the two datasets. However, some quantitative differences can be noted. The peak of rainfall in the northwestern Amazonia is lower in TRMM PR (around $2600 \mathrm{~mm}$ ) than in GPCP data (around $3000 \mathrm{~mm}$ ). Also, the covering area of high rainfall in this region is smaller for TRMM PR data than for GPCP data. Over the southern Brazil, the area of high rainfall is larger in TRMM PR compared with GPCP data. The maximum rainfall in this region is higher in TRMM PR (higher than $2400 \mathrm{~mm}$ ) than in GPCP (around $2000 \mathrm{~mm}$ ). Both the data sources show low rainfall of around $1200 \mathrm{~mm}$ in the southeast Brazil $\left(15^{\circ} \mathrm{S}, 45^{\circ} \mathrm{W}\right)$. The highest rainfall over west Colombia is well represented in TRMM PR and GPCP, in agreement with the study by Figueroa and Nobre (1990) using 226 rain gauge stations well distributed over the northwestern Amazonia. The high values of rainfall over northern SA are lower in TRMM PR (around $1400 \mathrm{~mm}$ ) than in GPCP (higher than $2000 \mathrm{~mm}$ ). Over western (eastern) SA although the rainfall pattern is similar in both data sources the GPCP values are less than (exceed) TRMM PR values.

Figure 2(c) shows that in general the differences of the rainfall estimates, GPCP minus TRMM TR, are positive over SA. However, over the Pacific coast of SA and the southern Brazil, GPCP rainfall is lower than TRMM estimates. This is in agreement with $\mathrm{Li}$ and $\mathrm{Fu}$ (2005). As seen in figure 2(c), large positive differences between GPCP and TRMM PR are noted over north SA (higher than $+500 \mathrm{~mm}$ ), northwestern and central Amazonia (around $+400 \mathrm{~mm}$ ), which is a region characterized by strong convective activity. Significant negative differences (higher than $-400 \mathrm{~mm}$ ) are seen in the Pacific coastal regions of SA and over the southern Brazil. $\mathrm{Li}$ and $\mathrm{Fu}$ (2005) suggested that the negative differences are usually 

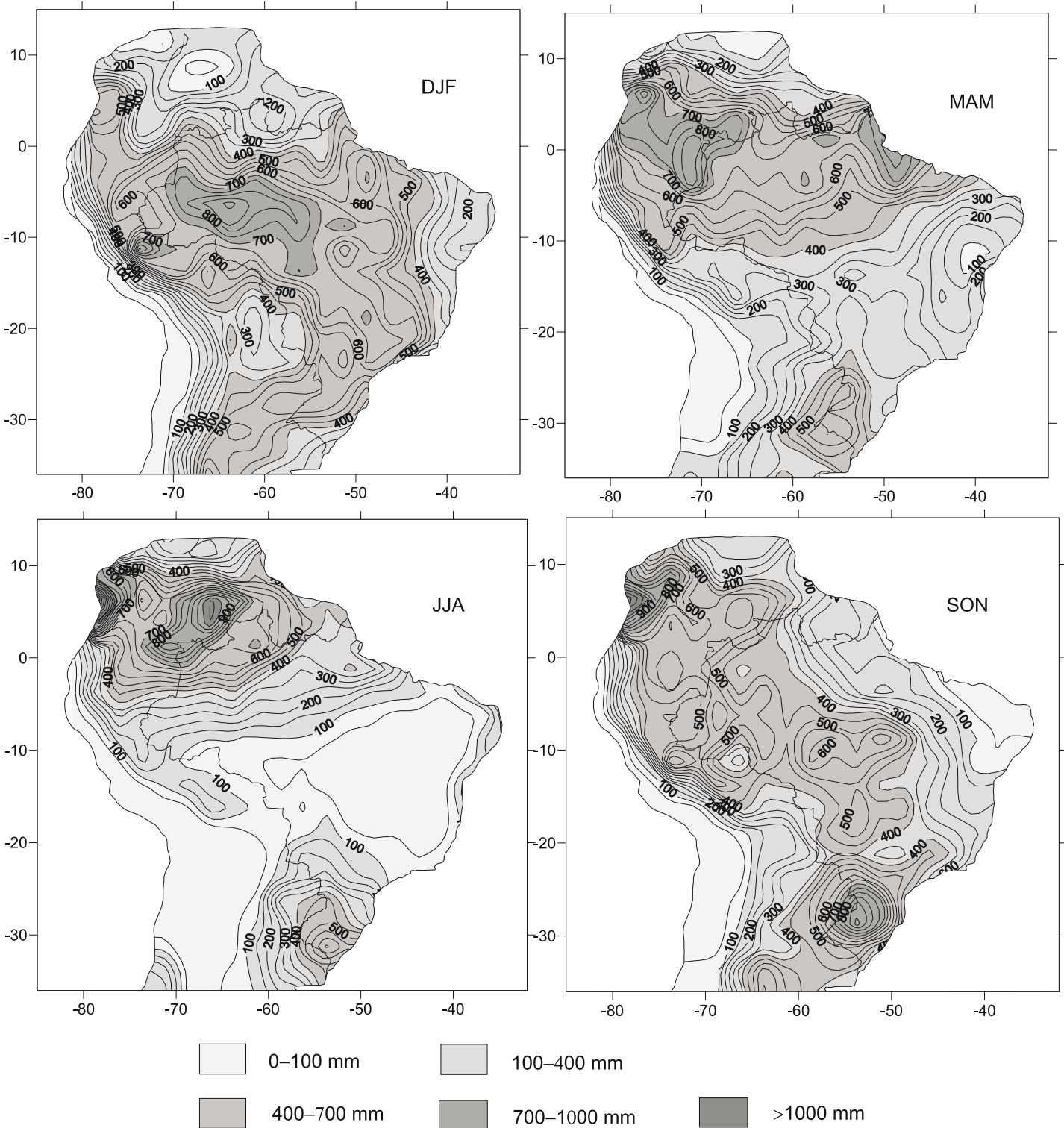

$100-400 \mathrm{~mm}$

$700-1000 \mathrm{~mm}$

Figure 3. TRMM seasonal mean precipitation (mm) (1998-2005): (a) DJF, (b) MAM, (c) JJA, and (d) SON.

located in areas with sparse or even no rain gauge stations, while in the regions with dense rain gauge stations positive differences dominate. However, we suggest that these differences are mainly due to the use of the satellite observations in GPCP and the random errors in TRMM PR. As mentioned earlier, satellite observations based on IR and OLR sensors contribute to an overestimation of convective rainfall. This may be the cause for the higher rainfall in GPCP than in TRMM PR over north SA, northwest Amazonia and central Brazil, where strong convective rainfall dominates. As can be seen in figure 1, the rain gauge station distribution is sparse in the Amazonia and central Brazil. So, the positive differences cannot be attributed to a dense rain gauge network, as suggested by Li and Fu (2005). On the other hand, in southern Brazil there are a large number of rain gauge stations (figure 1). Again, the negative difference GPCP minus TRMM PR cannot be due to the sparse data coverage, as mentioned by $\mathrm{Li}$ and $\mathrm{Fu}$ (2005). In regions like southern Brazil GPCP data are mainly based on rain gauge stations. Thus, the negative differences GPCP minus TRMM PR are due to the random errors in PR rainfall estimates. In this region PR rainfall estimates overestimate ANEEL rainfall data (Franchito et al 2009). From figures $2(a, b)$ and $(d)$, it is seen that in general GPCP rainfall estimates are in better agreement with ANEEL data (1979-2000) than TRMM PR in the regions with a dense concentration of rain gauge stations, whereas in the areas with a sparse distribution of rain gauge stations TRMM PR rainfall estimates are closer to ANEEL data. These are 

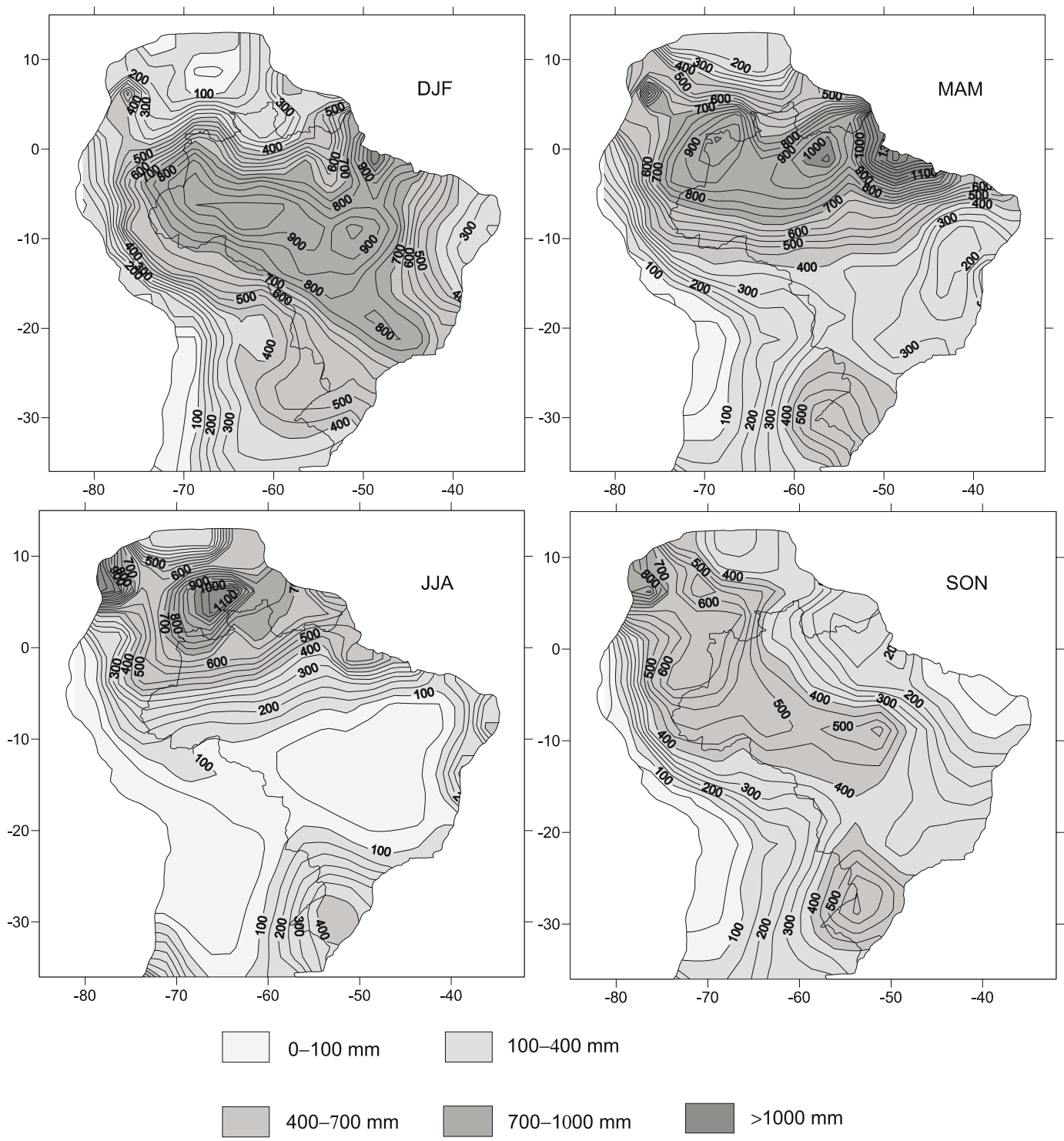

Figure 4. Same as in figure 2, but for GPCP data.

in agreement with the errors in TRMM PR and GPCP discussed in section $2 \mathrm{a}$.

The results showed above considered TRMM PR and GPCP data for the mean period (1998-2005) and the mean period (1979-2000) for ANEEL data. However, the comparison between the mean rainfall considering the same period (1998-2000) for TRMM PR, GPCP and ANEEL data also shows similar conclusions (figures not shown).

Figures $3(\mathrm{a}-\mathrm{d})$ and $4(\mathrm{a}-\mathrm{d})$ show seasonal variations in TRMM PR and GPCP data, respectively. The differences GPCP minus TRMM PR are showed in figure $5(\mathrm{a}-\mathrm{d})$. Both data sources show in DJF a region of maximum rainfall over central Brazil with northwest to southeast orientation (figures $3 \mathrm{a}$ and $4 \mathrm{a}$ ), indicating that they reproduce correctly the of the south Atlantic convergence zone (SACZ). The high rainfall of around $950 \mathrm{~mm}$ is divided in two centers in GPCP data, while in TRMM PR only one center is seen. A peculiar feature, which is noted in figures 3(a) and 4(a), is that in both TRMM PR and GPCP data the high rainfall area extends towards the north-northeast of Brazil $\left(5^{\circ} \mathrm{S}, 50^{\circ} \mathrm{W}\right)$. Over these region a center of maximum rainfall of about $750 \mathrm{~mm}$ is seen in TRMM PR, while in GPCP data the rainfall is stronger (higher than $900 \mathrm{~mm}$ ). As in the case of the mean annual rainfall, the area of high values is smaller in TRMM PR. The two data sources reproduce the high rainfall during the rainy season (MAM) over the north-northeast Brazil (figures 3b and $4 \mathrm{~b}$ ), although the maximum rainfall in GPCP data exceeds TRMM PR. The two data sources reproduce well the dry season over most of Brazil during JJA (figures $3 \mathrm{c}$ and $4 \mathrm{c}$ ) and the high rainfall (higher than $1000 \mathrm{~mm}$ ) over the northwest SA. 

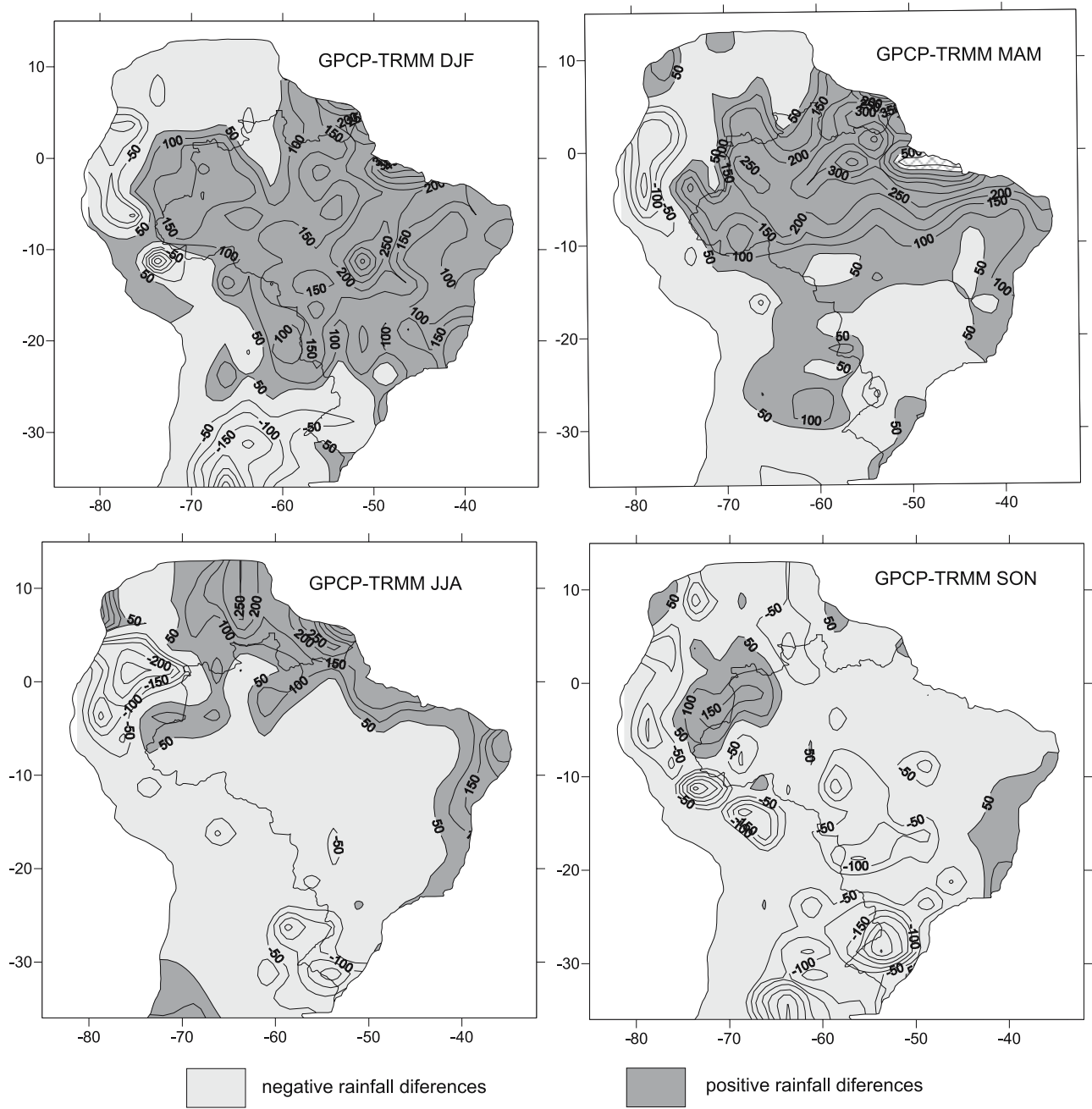

Figure 5. GPCP minus TRMM seasonal mean precipitation (1998-2005).

In JJA and SON (figures 3d and 4d) the two data sources show a maximum rainfall over the southern Brazil. However, the values of rainfall are higher in TRMM PR compared with GPCP data, as in the case of mean annual rainfall. Over the northern and eastern SA, the rainfall distribution in TRMM $\mathrm{PR}$ is similar to that in GPCP data in all the four seasons, although the values of rainfall are lower, in general, in TRMM PR.

Table 1 shows the mean annual and mean seasonal correlation coefficients (c.c) between GPCP and TRMM PR for five regions of SA (figure 6). As can be noted, the c.c mean annual values are higher than $70 \%$ (significant at $99 \%$ by the twosided $t$ test confidence level) in the five regions. The c.cs are lower in the north region of Brazil and north SA (75\% and 70\%, respectively) and higher in south Brazil (96\%). The mean seasonal c.c values are, in general, higher than $80 \%$ (significant at $99 \%$ by the two-sided test confidence level). The lowest c.c values occur in north SA. Table 2 shows the mean annual SDs, BIAS and RMSE (GPCP minus TRMM) for the same five regions. As can be noted the SDs are higher in the north and northwest SA $\left(1.15 \mathrm{~mm}\right.$ day $^{-1}$ and $0.97 \mathrm{~mm} \mathrm{day}^{-1}$, respectively), while the values of BIAS are higher in the north and northeast regions of Brazil (around $1.0 \mathrm{~mm} \mathrm{day}^{-1}$ ). The RMSE values are higher in the north region of Brazil $\left(7.24 \mathrm{~mm} \mathrm{day}^{-1}\right)$ and north SA $\left(5.21 \mathrm{~mm} \mathrm{day}^{-1}\right)$. This is in agreement with the differences between GPCP and TRMM PR showed in figure 2 .

The results presented above show that there is a high correlation between GPCP and TRMM $\mathrm{PR}$ rainfall data in almost all the regions of SA, although quantitative differences occur over several regions of SA. In most parts of SA, GPCP rainfall is higher compared to TRMM PR. The higher differences occur in the north and northwest SA and in the north region of Brazil. In these regions rainfall is predominantly convective. The use of IR and OLR based observations in GPCP causes an overestimation of convective precipitation due to 
Table 1. Mean annual and seasonal correlation coefficients (\%) between GPCP and TRMM rainfall estimates for five regions of $S A$, showed in figure 6 . The asterisk represents correlation significant at $95 \%(*)$ and $99 \%(* *)$ confidence level by the two-sided $t$ test.

\begin{tabular}{lccccc}
\hline Region & $\begin{array}{c}\text { Mean } \\
\text { annual }\end{array}$ & DJF & MAM & JJA & SON \\
\hline South Brazil & $96^{* *}$ & $67^{*}$ & $82^{* *}$ & $84^{* *}$ & $98^{* *}$ \\
Northeast Brazil & $88^{* *}$ & $97^{* *}$ & $97^{* *}$ & $84^{* *}$ & $87^{* *}$ \\
North region of Brazil & $75^{* *}$ & $90^{* *}$ & $90^{* *}$ & $97^{* *}$ & $87^{* *}$ \\
North South America & $70^{* *}$ & $89^{* *}$ & $76^{* *}$ & $81^{* *}$ & $94^{* *}$ \\
Northwest South America & $83^{* *}$ & $95^{* *}$ & $82^{* *}$ & $89^{* *}$ & $82^{* *}$ \\
\hline
\end{tabular}

Table 2. Mean annual SDs, BIAS and RMSE between GPCP and TRMM rainfall estimates $\left(\mathrm{mm} \mathrm{day}^{-1}\right)$ for the same regions of table 1 . Also shown is the number of data points in each region.

\begin{tabular}{lcccc}
\hline Region & $\begin{array}{c}\text { Number of } \\
\text { data points }\end{array}$ & SD & BIAS & RMSE \\
\hline South Brazil & 10 & 0.67 & -0.49 & 1.56 \\
Northeast Brazil & 20 & 0.47 & 1.00 & 4.49 \\
North region of Brazil & 51 & 0.68 & 1.10 & 7.84 \\
North South America & 52 & 1.15 & 0.72 & 5.21 \\
Northwest South America & 53 & 0.97 & 0.36 & 2.63 \\
\hline
\end{tabular}

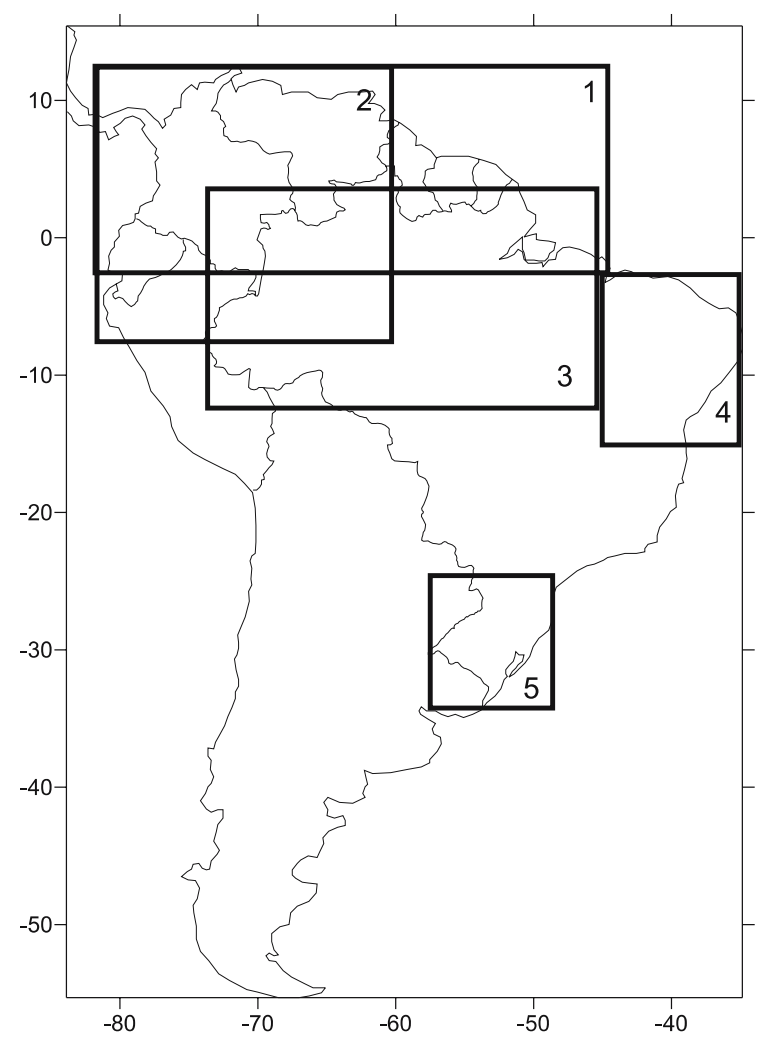

Figure 6. Location of five regions of SA: North South America (1), Northwest South America (2), North region of Brazil (3), Northeast Brazil (4), and South Brazil (5).

the presence of high cirrus cloud. Since TRMM $\mathrm{PR}$ is better at taking into account the vertical structure of the rain systems (Adler et al 2000), it is able to capture convective rainfall areas. Thus in these regions the TRMM PR rainfall estimates are more reliable than in GPCP. Although GPCP and TRMM PR show a strong correlation in southern Brazil $(96 \%$, significant at $99 \%$ by the two-sided $t$ test confidence level), rainfall estimates by GPCP are less than by TRMM PR. In this region the random errors in TRMM PR are high (Franchito et al 2009).

\section{Rainfall over SA during $1997 / 98$ El Niño and 1998/99 La Niña}

Figure $7(\mathrm{a}-\mathrm{c})$ shows the rainfall anomalies in the latter phase of the 1997/98 El Niño (JFMA 98) in TRMM PR, GPCP and ANEEL data, respectively. The same is plotted in figures $8(\mathrm{a}-\mathrm{c})$, but for the latter phase of the 1998/99 La Niña (JFMA 99). The TRMM PR and GPCP rainfall anomalies are obtained for the period (1998-2005). Since the ANEEL data are available only up to year 2000 , the anomalies are obtained from the long-term mean (1979-2000). It can be seen from figure $7(\mathrm{a}-\mathrm{c})$ that in JFMA 98 the rainfall was higher (positive anomalies) over the southern Brazil and it was lower (negative anomalies) in the eastern and western Brazil. Positive anomalies over the northwest Equator are also seen in TRMM PR and GPCP data. The rainfall was lower in the southern parts 

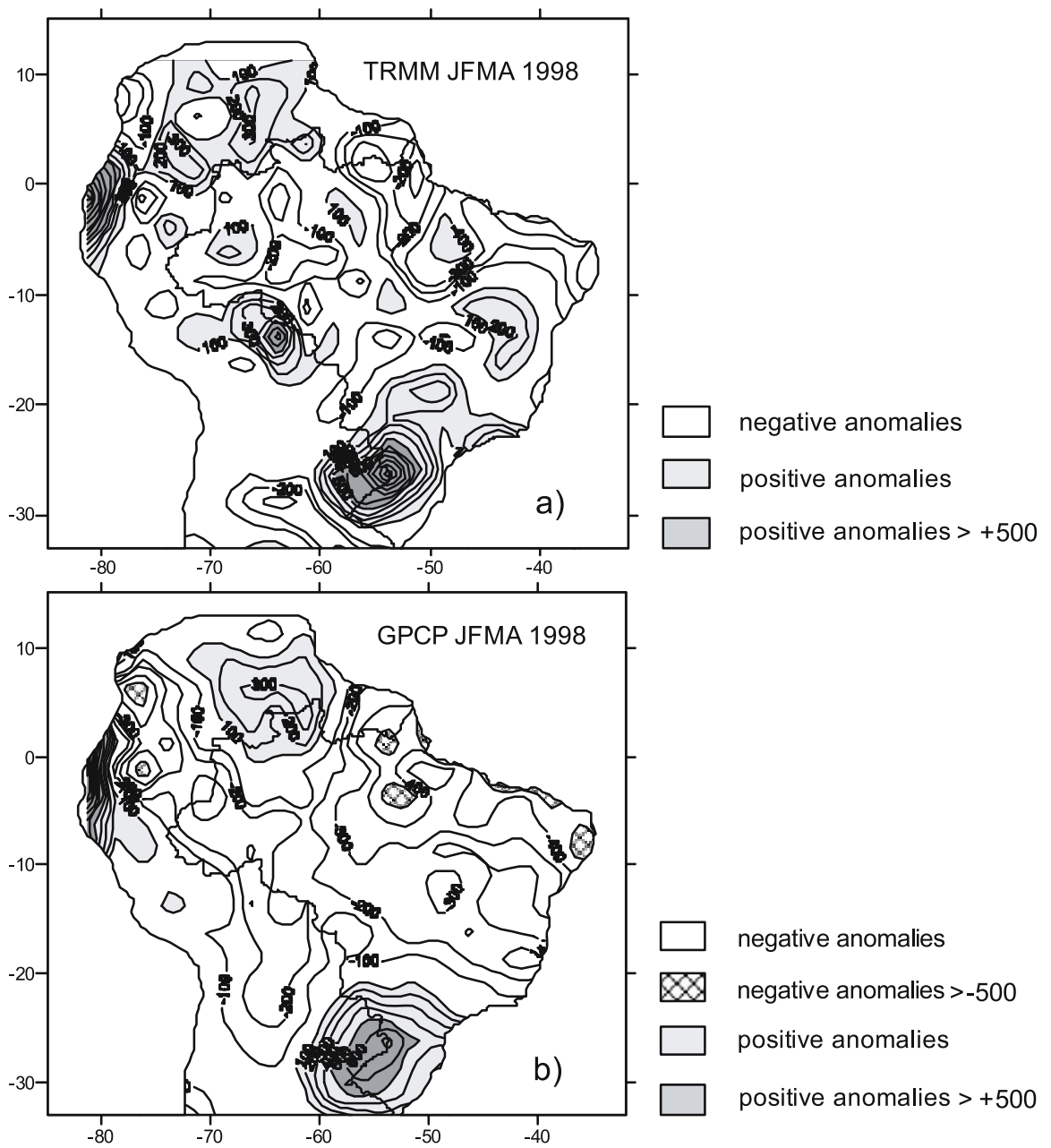

negative anomalies

negative anomalies $>-500$

positive anomalies

positive anomalies $>+500$

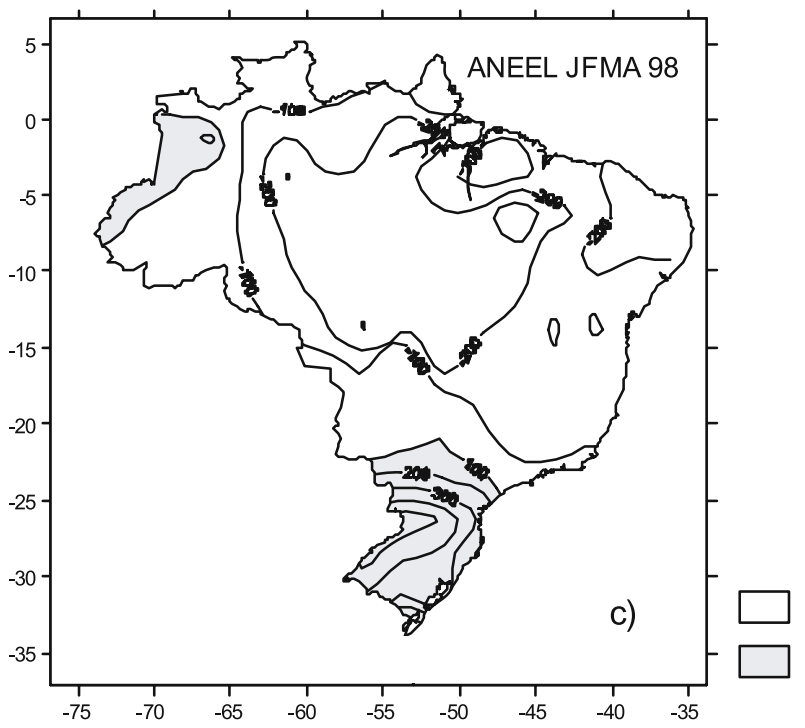

negative anomalies

positive anomalies

Figure 7. Anomaly of JFMA 1998 rainfall relative to the mean (JFMA 1998-2005) for: (a) TRMM, (b) GPCP, and relative to the mean (1979-2000) for: (c) ANEEL.

of Brazil and the rainfall was higher in the northwestern Brazil in JFMA 99 (figure 8a-c). These are some of the well-known features associated with the ENSO events (Ropelewski and Halpert 1987; Aceituno 1988; Rao and Hada 1990).
Despite the rainfall anomalies distribution during El Niño/La Niña episodes is in general well reproduced in the three data sources, there are some quantitative differences. As can be noted in figure $7(\mathrm{a}-\mathrm{c})$, although the region of higher 


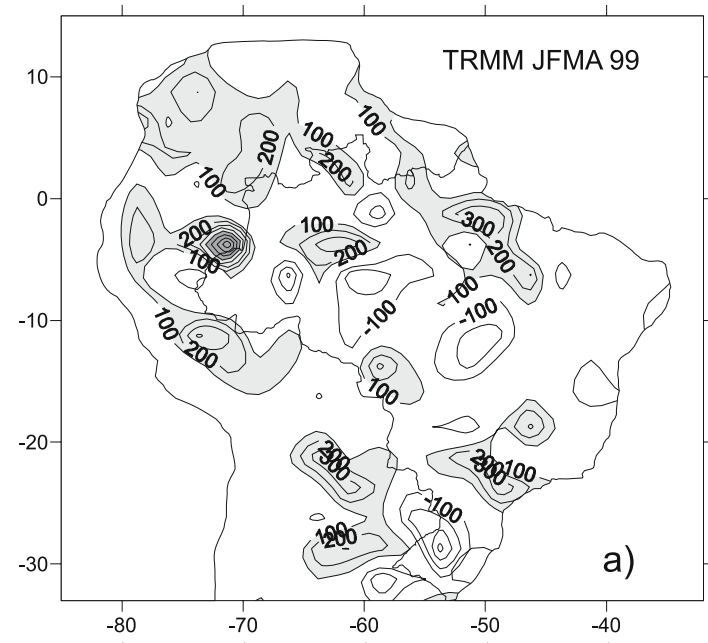

\section{negative anomalies \\ positive anomalies \\ positive anomalies $>+500$}

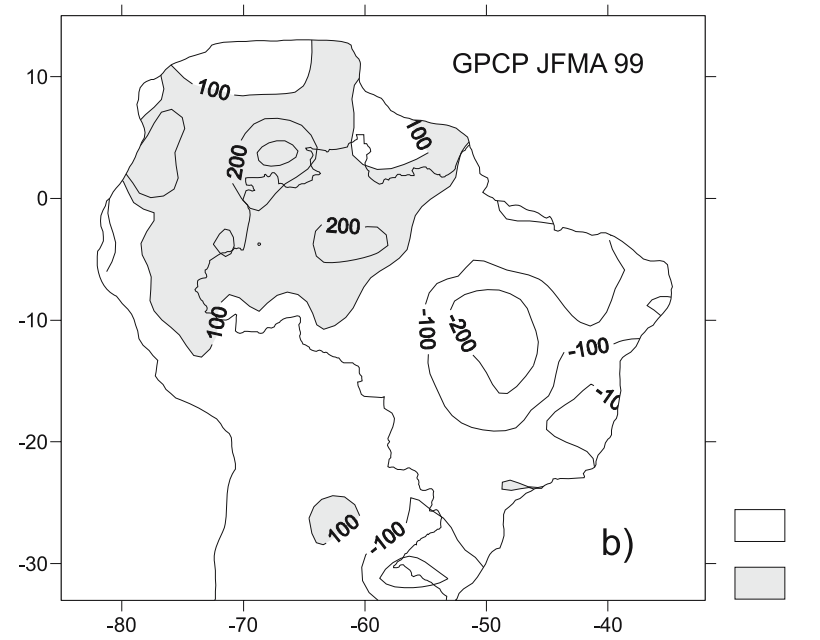

negative anomalies

positive anomalies

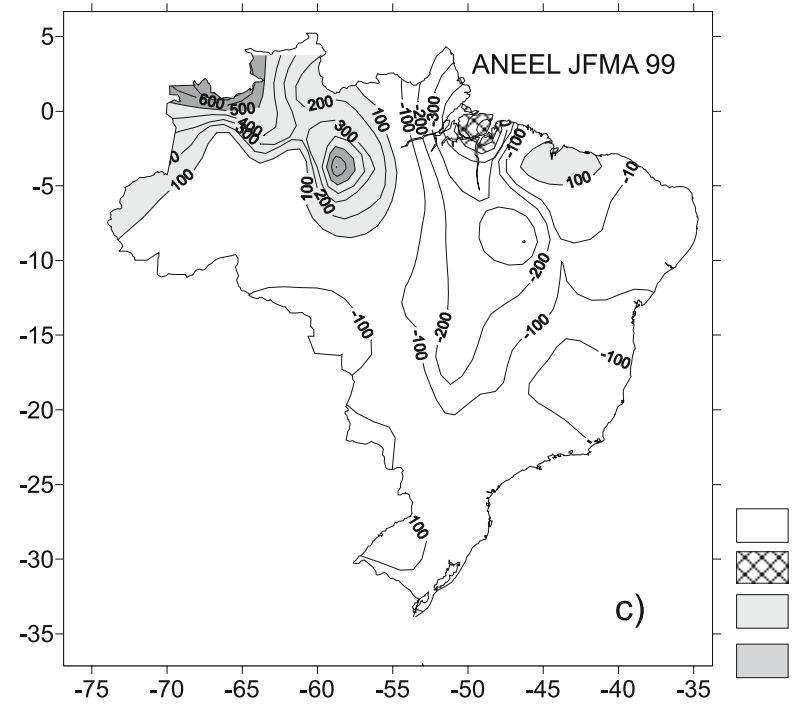

negative anomalies

negative anomalies $>-500$

positive anomalies

positive anomalies $>+500$

Figure 8. Same as in figure 6, but for JFMA 1999.

rainfall in the southern Brazil in JFMA 98 is similar in all the data sources, the area and values of rainfall anomalies are larger in TRMM PR compared with GPCP and ANEEL data. Negative departures (around $-400 \mathrm{~mm}$ ) are found over the entire northeast Brazil in GPCP data, while in TRMM PR the negative departures are smaller (between -100 and $-300 \mathrm{~mm}$ ) and a center of positive departures (about $+200 \mathrm{~mm}$ ) is seen. As in the case of GPCP data, negative anomalies are seen over the entire northeast Brazil in ANEEL data. However, they are smaller (maximum is around 


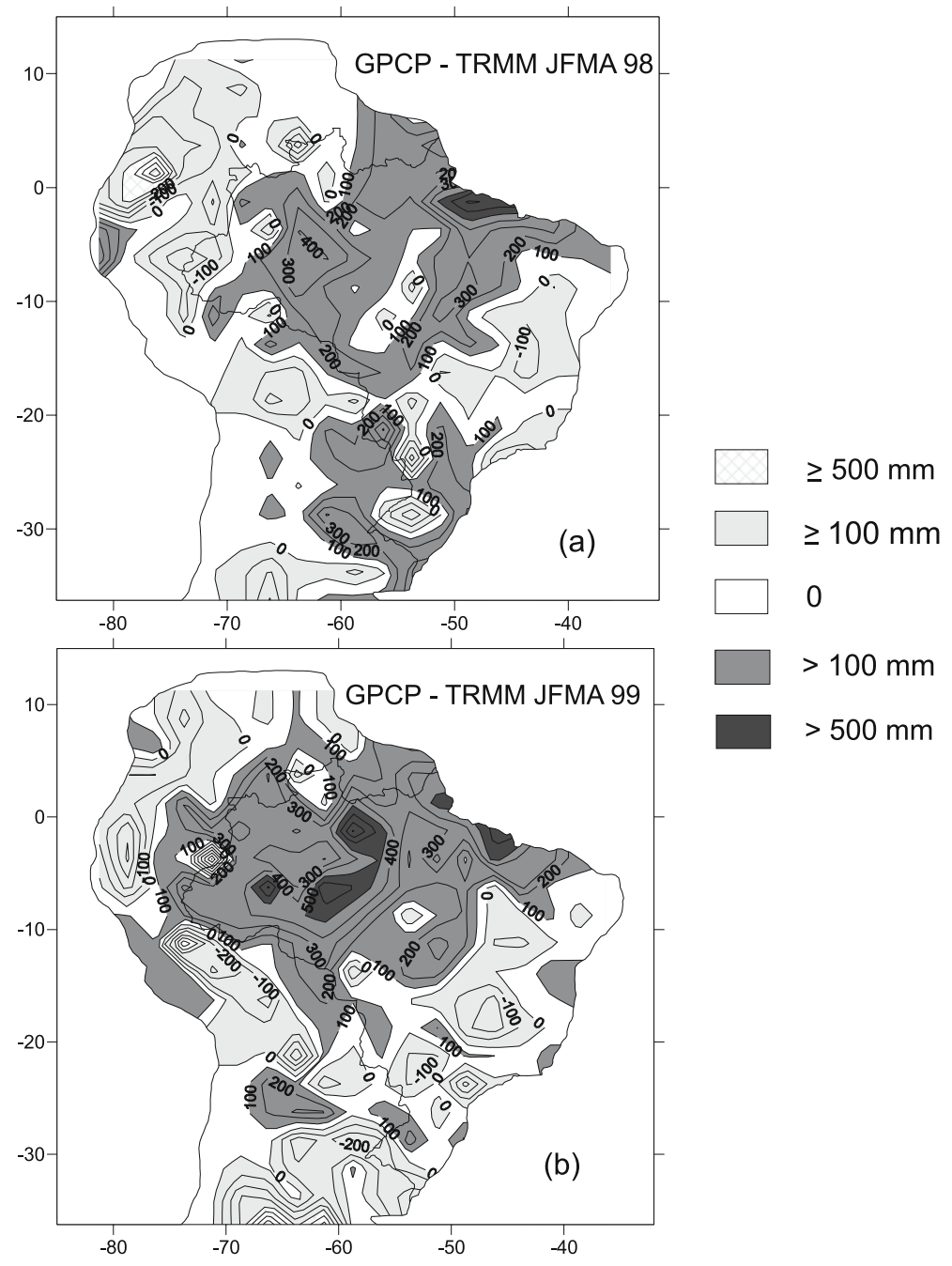

Figure 9. Difference (GPCP rainfall minus TRMM PR rainfall) during: (a) JFMA98, and (b) JFMA99.

$-200 \mathrm{~mm}$ ). Negative rainfall anomalies (between -100 and $-200 \mathrm{~mm}$ ) are found over most of the central and northwest Brazil in TRMM PR, although there some centers of smaller positive rainfall anomalies. In GPCP data negative departures (between -100 and $-300 \mathrm{~mm}$ ) are seen in the entire region. Again, the rainfall anomalies distribution in GPCP is similar to that in ANEEL data. However, the values of negative rainfall anomalies are smaller in GPCP. As mentioned earlier, rain gauge station distribution is sparse over the western and central parts of Brazil, thus a detailed analysis cannot be made with ANEEL data. Also, due to the use of IR and OLR radiance sensors an overestimation of the rainfall in GPCP data occurs in these regions. A region of positive anomalies, which extends from Peru to Bolivia, is seen in TRMM PR. In GPCP data these positive anomalies occur only in a small region over Peru and these values are lower than in TRMM PR.

From figure $8(\mathrm{a}-\mathrm{c})$ it can be noted that in the region of lower rainfall over the southern Brazil in JFMA 99 negative rainfall anomalies of about $-300 \mathrm{~mm}$ are seen in TRMM PR. The negative departures are smaller in GPCP and ANEEL data (around $-100 \mathrm{~mm}$ ). Over the northwest SA a broad region of positive rainfall anomalies (between +100 and $+300 \mathrm{~mm}$ ) is seen in GPCP data, while in TRMM PR there are centers of negative and positive anomalies. Over the northwestern Brazil a strong maximum of positive rainfall anomalies (higher than $+500 \mathrm{~mm}$ ) is found in TRMM PR, which is not seen in GPCP data. A region of strong positive anomalies over Amazonia is also seen in ANEEL data, but it is shifted eastward compared with TRMM PR. However, due to the scarcity of the distribution of rain gauge stations in this region in ANEEL data the analysis is not reliable. Over central Brazil negative anomalies (around $-200 \mathrm{~mm}$ ) are present in TRMM PR. In GPCP and ANEEL data the area of these negative anomalies is broader and their values are higher. A region of positive rainfall anomalies of about $250 \mathrm{~mm}$ over southeast Brazil is found in TRMM 
PR data. In GPCP and ANEEL data this region is not seen.

The results showed above indicate that the well-known qualitative features associated with ENSO events are correctly reproduced by all the three data sources. However, in most of the SA GPCP rainfall anomalies exceed TRMM PR rainfall anomalies, although there are regions where the opposite occur (particularly in the southern Brazil), with a general agreement that was noted in the mean annual case (see section 3). The areas of positive and negative anomalies are broader in GPCP data. Due to the fact that TRMM PR provides information on the three-dimensional structure of the rain systems it is able to capture several centers of positive and negative anomalies (with a smaller area). The distribution of the rainfall anomalies in GPCP is in general similar to that in ANEEL data, mainly in the regions where there is a dense concentration of rain gauge stations. These results are in agreement with the errors of the data sources discussed in section 2a. GPCP random errors are larger in the central Brazil and north-northwest Amazonia and lower in the southern Brazil while TRMM PR SD values are lower in the central and north-northwest Brazil compared to those in the southern Brazil (where they are the largest).

$\mathrm{Li}$ and $\mathrm{Fu}$ (2005) observed that the rainfall is greatly overestimated in the tropical Pacific by GPCP than by TRMM PR in the latter phase of the 1997/98 El Niño compared with the latter phase of the 1998/99 La Niña. This does not occur over the SA continent. From figure $9(\mathrm{a}-\mathrm{b})$ it can be noted that in the particular case of Brazil the higher positive differences between GPCP and TRMM PR occur in central Amazonia in the La Niña case. During the El Niño the rainfall (and consequently the convection) decreases in this region. Thus, there is a reduction in the overestimation of the convective rainfall by GPCP so that the positive differences between the two data sources are reduced. Over southern Brazil the negative differences between GPCP and TRMM PR are higher in the El Niño case. During the El Niño episode the rainfall increases in this region. Thus, the overestimation of rainfall by TRMM PR increases so that the negative differences GPCP minus TRMM PR increase. This agrees with the larger TRMM PR SDs and the lesser GPCP random errors in this region.

\section{Conclusions}

In this study a detailed diagnosis of rainfall over SA during the 1997/98 El Niño and 1998/99 La Niña events using TRMM PR data was made. The potentialities and limitations of TRMM PR data were evaluated comparing with rain gauge station data from ANEEL and combined satellite/station data from GPCP. First, the characteristics of the mean annual rainfall (1998-2005) in TRMM PR and GPCP data were analyzed. Although, there was a high correlation between TRMM PR and GPCP rainfall, some quantitative differences were noted. It was found that differences between the GPCP and TRMM PR rainfall estimates are in general positive over most part of SA. However, there are regions where rainfall in GPCP is lower than in TRMM PR. Over north SA the rainfall is overestimated by GPCP compared with TRMM PR. In the particular case of Brazil, the northwestern and central (southern) region GPCP rainfall exceeds (is less than) TRMM PR.

In an earlier study, $\mathrm{Li}$ and $\mathrm{Fu}$ (2005) pointed out that the negative differences between GPCP and TRMM PR rainfall estimates are usually located in areas with sparse or even no rain gauge stations, while in the regions with dense rain gauge stations positive differences dominate. In the present study, we suggest that the cause for the positive differences between GPCP and TRMM PR rainfall are related to the fact that the satellite observations based on IR and OLR radiance sensors contribute to overestimate convective rainfall in GPCP. This explains the higher rainfall in GPCP than in TRMM PR over northwest Amazonia and central Brazil and over north SA, where strong convective rainfall dominates. On the other hand, over the southern Brazil GPCP rainfall is close to ANEEL rain gauge data. So, the cause for the negative differences GPCP minus TRMM $\mathrm{PR}$ is attributed to the large random errors in TRMM PR (PR estimates overestimate ANEEL rain gauge data). Computed values of SD, BIAS and RMSE indicated that the higher quantitative differences between GPCP and TRMM PR occur in the regions with strong convective activity.

The analysis of the rainfall anomalies during the latter phase of the 1997/98 El Niño (JFMA 98) and the 1998/99 La Niña (JFMA 99) showed that TRMM PR, GPCP and ANEEL data reproduce the main features of ENSO events. However, some differences in the location and magnitude of rainfall anomalies were noted. The rainfall anomalies are generally higher in GPCP than in TRMM PR, although as in the mean annual case there are regions where the rainfall in GPCP is lower than in TRMM PR. The areas of positive and negative anomalies are broader in GPCP data compared with TRMM PR. Since TRMM PR provides information on the three-dimensional structure of the rain systems it is able to capture several centers of positive and negative anomalies, mainly in the regions with strong convective activity. The higher 
positive (negative) differences between the rainfall anomalies in GPCP and TRMM PR, which occur in the central Amazonia (southern Brazil), are reduced (increased) in the El Niño case. During the El Niño event there is a decrease (increase) of the rainfall in the central (southern Brazil). Consequently, there is a reduction of the overestimation of the convective rainfall in the central Brazil by GPCP and an increase of the overestimation in the southern Brazil by TRMM PR. The rainfall anomalies distribution is similar in GPCP and ANEEL data, mainly in the regions with a dense concentration of meteorological stations.

Thus it can be concluded that over SA in the regions with high convective activity the use of monthly mean estimates by TRMM PR is more adequate than by GPCP while the use of GPCP data is more appropriate in the regions with a dense concentration of rain gauge stations.

\section{Acknowledgement}

The third author was supported by Fundação de Amparo à Pesquisa do Estado de São Paulo (FAPESP).

\section{References}

Aceituno P 1988 On the functioning of the SouthernOscillation in the South America sector. Part I: Surface climate; Mon. Wea. Rev. 116 505-524.

Adler R F, Huffman G J, Bolvin D T, Curtis S and Nelkin E J 2000 Tropical rainfall distribution determined using TRMM combined with other satellite and rain gauge information; J. Appl. Meteor. 39 2007-2023.

Adler R F and Coauthors 2003 The Version-2 Global Precipitation Climatology Project (GPCP) monthly precipitation analysis (1979-present); J. Hydrometeor. 4 $1147-1167$.

Arkin P A and Meisner B N 1987 The relationship between large-scale convective rainfall and cold cloud over the western hemisphere during 1982-84; Mon. Wea. Rev. 115 $51-74$.

Bell T L, Abdullah A, Martin R L and North G 1990 Sampling errors for satellite-derived tropical rainfall: Monte Carlo study using a space-time stochastic model; J. Geophys. Res. 95 2195-2205.

Bell T L and Kundu P K 2000 Dependence of satellite sampling error on monthly averaged rain rates: Comparison of simple models and recent studies; J. Appl. Meteor. 13 449-462.

Bell T L, Kundu P K and Kummerow C D 2001 Sampling errors of SSM/I and TRMM rainfall averages: comparison with error estimates from surface data and a simple model; J. Appl. Meteor. 13 449-462.

Coughlan M J 1999 Retrospective on the 1997/1998 El Niño event; CLIVAR Exchanges 4 7-8.

Ferrraro R and Marks G 1995 The development of SSM/I rainrate retrieval algorithm using groundbased radar measurements; J. Atmos. Oceanic. Technol. 12 755-770.
Ferraro R, Weng F, Grody N C and Basist A 1996 An eightyear (1987-1994) time series of rainfall, clouds, water vapor, snow cover, and sea ice derived from SSM/I measurements; Bull. Amer. Meteor. Soc. 77 891-905.

Figueroa S N and Nobre C A 1990 Precipitation distribution over central and western tropical South América; Climanálise 5 36-40.

Franchito S H, Rao V B, Barbieri P R B and Santo C M E 2008 Rainy season duration estimated from OLR versus rain gauge data and the 2001 drought in Southeast Brazil; J. Appl. Meteor. Climatol. 47 1493-1499.

Franchito S H, Rao V B, Vasques A C, Santo C M E and Conforte J C 2009 Validation of TRMM PR monthly rainfall estimates over Brazil; J. Geophys. Res. 114 D02105, doi:10.1029/2007JD009580.

Fu Y and Liu G 2001 The variability of tropical precipitation profiles and its impact on microwave brightness temperatures as inferred from TRMM data; J. Appl. Meteor. 40 2130-2143.

Fu Y and Liu G 2003 Precipitation characteristics in midlatitude East Asia as observed by TRMM PR and TMI; J. Meteor. Soc. Japan 81 1351-1367.

Fu Y, Lin Y H, Liu G and Wang Q 2003 Seasonal characteristics of precipitation in 1998 over East Asia as derived from TRMM PR; Adv. Atmos. Sci. 20 511-529.

Grimm A M, Ferraz S E T and Gomes J 1998 Precipitation anomalies in Southern Brazil associated with El Niño and La Niña events; J. Climate 11 2863-2880.

Huffman G J, Adler R F, Arkin P A et al 1997 The global precipitation climatology project; Bull. Amer. Soc. $\mathbf{7 8}$ $5-20$.

Iguchi, Toshio and Robert Meneghini 1994 Intercomparison of single-frequency methods for retrieving a vertical rain profile from airborne or space radar data; J. Atmos. Oceanic Technol. 11 1507-1516.

Iguchi T, Meneghini R, Awaka J and Okamoto K 2000 Rain profiling algorithm for the TRMM precipitation radar; J. Appl. Meteor. 39(Part 1) 2038-2052.

Kummerow C, Barnes W, Kozu T, Shiue J and Simpson J 1998 The Tropical Rainfall Measuring Mission (TRMM) sensor package; J. Atmos. Oceanic Technol. 15 809-817.

Kummerow C and Coauthors 2000 The status of the Tropical Rainfall Measuring Mission (TRMM) after two years in orbit; J. Appl. Meteor. 39 1965-1982.

Kummerow C, Poyner P, Berg W and Thomas-Stahle J 2004 The effects of rainfall inhomogeneity on climate variability of rainfall estimated from passive microwave sensors; J. Atmos. Oceanic Technol. 21 624-638.

Legates D R and Willmott C J 1990 Mean seasonal and spatial variability in gauge corrected, global precipitation; Int. J. Climatol. 10 111-127.

Li R and FU Y 2005 Tropical Precipitation Estimated by GPCP and TRMM PR Observations; Adv. Atmos. Sci. 22 852-864.

Marengo J, Liebmann B, Kousky V E, Filizola N and Wainer I 2001 On the onset and end of the rainy season in the Brazilian Amazon Basin; J. Climate 14 833-852.

Meneghini R, Iguchi T, Kozo T, Liao L, Okamoto $\mathrm{K}$, Jones J A and Kwiatkowski J 2000 Use of the surface reference technique for path attenuation estimates from the TRMM precipitation radar; J. Appl. Meteor. 39(Part 1) 2053-2070.

Neelin J D, Jin F-F and Syu H-H 2000 Variations in ENSO phase locking; J. Climate 13 2570-2590.

North G R and Nakamoto S 1989 Formalism for comparing rain estimation designs; J. Atmos. Oceanic Technol. 6 985-992. 
Rao V B and Hada K 1990 Characteristics of rainfall over Brazil: Annual variations and connections with the Southern Oscillation; Theor. Appl. Climatol. 42 81-91.

Rao V B, Santo C E E and Franchito S H 2002 A diagnosis of rainfall over South América during the 1997/98 El Niño event. Part I: Validation of NCEP-NCAR reanalysis rainfall data; J. Climate 15 502-511.

Ropelewski C F and Halpert M S 1987 Global and regional scale precipitation patterns associated with El Niño/Southern Oscillation; Mon. Wea. Rev. 115 $1606-1626$

Ropelewski C F and Halpert M S 1989 Precipitation patterns associated with the high index phase of Southern Oscillation; J. Climate 2 268-284.

Rudolf B 1993 Management and analysis of precipitation on a routine basis; Proc. Int. WMO/IAHS/ETH/SYMP. on Precipitation and Evaporation, Slovak Hydrometeorology Institute, Bratislava, 69-76.

Rudolf B, Hauschild H, Rueth W and Schneider U 1994 Terrestrial precipitation analysis: Operational method and required density of point measurements; In: Global Precipitations and Climate Change (eds) Desbois $\mathrm{M}$ and Desalmond F, NATO ASI Series I, 26, Springer-Verlag, pp. $173-186$.

Rudolf B, Fuchs T, Rueth W and Schneider U 1998 Precipitation data for verification of NWP model re-analyses: The accuracy of observational results; Proc. WCRP
International Conference on Reanalyses, Washington, DC, 27-31 October 1997, WMO/TD-No. 876, WCRP104, 215-218.

Shin K and North G R 1988 Sampling error study for rainfall estimate by satellite using a stochastic model; J. Appl. Meteor. 27 1218-1231.

Simpson J, Adler R F and North G R 1998 A proposed Tropical Rainfall Measuring Mission (TRMM) satellite; Bull. Amer. Meteor. Soc. 69 278-295.

Susskind J, Piraino P and Rokke P, Iredell T and Mehta A 1997 Characteristics of the TOVS pathfinder path A dataset; Bull. Amer. Meteor. Soc. 78 1449-1472.

Wang C and Weisberg R H 2000 The 1997-98 El Niño evolution relative to previous El Niño events; J. Climate $\mathbf{1 3}$ 488-501.

Wilheit T J, Chang A T C and Chiu L S 1991 Retrieval of monthly rainfall indices from microwave radiometric measurements using probability distribution functions; J. Atmos. Oceanic Technol. 8 118-136.

Xie P P and Arkin P A 1998 Global monthly precipitation estimates from satellite observed outgoing longwave radiation; J. Climate 11 137-164.

Zheng Yuanyuan, Fu Yunfei, Liu Yong, Zhu Hongfei, Xie Yifeng, Yao Xiuping and Yu Rucong 2004 Heavy rainfall structures and lightning activities in a cold front cyclone happened in Huai river derived from TRMM PR and LIS observations; Acta Meteorologica Sinica 62 790-802. 